\title{
Professed religious affiliation and the practice of euthanasia
}

\author{
Peter Baume, Emma O'Malley and Adrian Bauman School of Community Medicine, University of New \\ South Wales
}

\begin{abstract}
Attitudes towards active voluntary euthanasia (AVE) and physician-assisted suicide (PAS) among 1,238 doctors on the medical register of New South Wales varied significantly with self-identified religious affiliation. More doctors without formal religious affiliation ('non-theists') were sympathetic to $A V E$, and acknowledged that they had practised AVE, than were doctors who gave any religious affiliation ('theists'). Of those identifying with a religion, those who reported a Protestant affiliation were intermediate in their attitudes and practices between the agnostic/atheist and the Catholic groups. Catholics recorded attitudes most opposed to AVE, but even so, 18 per cent of Catholic medical respondents who had been so requested, recorded that they had taken active steps to bring about the death of patients.
\end{abstract}

\section{Introduction}

Active voluntary euthanasia (AVE) covers the taking of active steps to hasten the death of another person. It contrasts with passive euthanasia in which specific allopathic treatment (but not good symptomatic care) is withdrawn or not commenced, and with physician-assisted suicide (PAS) in which the means are made available by a practitioner of medicine to someone wishing to end his/her own life.

Most established religions (the Anglican Church of Australia (1), the Roman Catholic Church $(2,3)$, Judaism $(4,5,6)$, Islam (7)), but not yet the Uniting Church in Australia (8), disapprove of AVE and have teachings specifically opposed to euthanasia and to suicide. To learn how the assertions of religious affiliation might be reflected in the practices and attitudes of registered medical practitioners in Australia we undertook this analysis, as part of a wider study on euthanasia, to investigate how, in New South Wales, those professing particular religious affiliations acknowledged that they responded to requests from patients for euthanasia or to other means for hastening death.

\section{Key words}

Euthanasia; religion.

\section{Methods}

The survey into attitudes and practices of 2,000 practitioners on the medical register of New South Wales has been described elsewhere (9). In answer to one question, 1,238 (97.5 per cent) practitioner respondents indicated their religious affiliation. Because the survey was based closely on one done in Victoria seven years ago to allow comparisons across time and states, there were no questions about the strength of religious affiliation, or about the frequency of religious observance. Answers from anonymous individual questionnaires were cross-tabulated to determine the significance of religious affiliation in answers to a range of specific questions about the practice of euthanasia and suicide and about attitudes of practitioners towards AVE and PAS. Analysis compared the proportions between the groups using Yates-corrected chi-squared statistics. Logistic regression models, using forced entry of independent variables, were developed to assess the likelihood of response to particular statements about euthanasia (10). Likelihood was presented as odds ratios (and their 95 per cent confidence intervals), after adjustment for the potential confounders of age, sex and type of practice of the responding doctors.

Of those who returned completed questionnaires, 20 identified themselves as being 'lapsed' - 15 Catholics, two Anglicans and three Jews. These people had not chosen to identify themselves as agnostic/atheist, although that option had been open to them. For purposes of analysis they were included as belonging still to their religion of birth - so measuring the long-term consequences of childhood and adolescent exposure to particular religious teaching within families. The questionnaire did not distinguish between atheism and agnosticism - a grouping together that was commented upon adversely by some respondents.

\section{Results}

After exclusions were made for wrong addresses, deaths, practitioners out of Australia, and for an estimate of the number who failed to receive the questionnaires, the initial sample of 2,000 doctors reduced to 1,656 from which 1,268 answers were 
Table 1

Religious affiliations of $1,238 \mathrm{NSW}$ medical practitioners

\begin{tabular}{llccc} 
& & \multicolumn{2}{c}{ Sample studied } & All NSW \\
\cline { 3 - 5 } & & Number & Percentage & Percentage \\
Agnostic/atheist & & 362 & $29 \cdot 2$ & $10 \cdot 0$ \\
Christian & Catholic & 240 & $19 \cdot 4$ & $29 \cdot 5$ \\
& Anglican & 230 & $18 \cdot 6$ & $27 \cdot 3$ \\
& Other & 199 & $16 \cdot 1$ & $15 \cdot 3$ \\
Non-Christian & Protestant 'Christian' & 22 & $1 \cdot 8$ & N/A \\
& Jewish & 60 & $4 \cdot 8$ & $0 \cdot 5$ \\
& Hindu & 45 & $3 \cdot 6$ & 0 \\
All others & Buddhist & 15 & $1 \cdot 2$ & $1 \cdot 0$ \\
No answer & Moslem & 11 & $0 \cdot 9$ & $1 \cdot 4$ \\
& & 54 & $4 \cdot 4$ & $5 \cdot 8$ \\
& & & & $9 \cdot 1$ \\
\cline { 3 - 5 } & Total & 1238 & 100 & $99 \cdot 9$
\end{tabular}

${ }^{\star}$ NSW population percentages obtained from Australian Bureau of Statistics (14).

received before the cut-off date, giving an overall response rate of 76.6 per cent. If those who had not received the questionnaires were not excluded, the sample reduced only to 1,945 and the response rate became $65 \cdot 2$ per cent.

Self-identified religious affiliations of the 1,238 medical practitioners are shown in Table 1 .

While slightly different percentages of those claiming adherence to different religions were found among the various age groups, the differences were slight and not significant. As religious affiliation was related to age group and to type of practice (but not to gender), adjusted analyses are now reported.

Aggregating respondents into two groups -876 'theists' and 362 'non-theists' we compared the answers of those who professed any religion with those who identified themselves as agnostic or atheist. The differences are set out in Table 2.

Overall, 543 of 1,159 respondents had been asked by patients to hasten death, and 27.9 per cent of these reported that they had taken active steps to hasten death, a figure which is comparable with that reported from Victoria in 1988 (11). Of those identifying as agnostic or atheist who had been asked to hasten death, more than one third ( 34.6 per cent) recorded that they had taken active steps to comply with such a request at least once, compared to just under a quarter (24.7 per cent) of those who identified a religious affiliation. The 'non-theists' were 1.6 times as likely to practise AVE as were all 'theists'. Only 18 per cent of those who identified themselves as Catholic, 28 per cent of Anglicans, 25 per cent of other Protestants, 22 per cent of other Christians, 35 per cent of Jews and 35 per cent of Moslems had taken active steps to hasten death. Those who classed themselves as 'lapsed' did not behave significantly differently from the rest.

'Non-theists' were more than twice as likely to know of other doctors who practised AVE, and wege more than three times more likely to think AVE sometimes right, compared to 'theist' practiti (Table 2). 'Non-theists' were significantly mồ likely to favour the Dutch arrangements an $\overline{\text { F }}$ fo indicate support for professional responsibilify regarding euthanasia policies and the need for legl changes, compared to all 'theist' doctors (Table 2.

Those identifying with different religions weje then analysed separately. Because numbers were small in some groups, the differences did not reach significant levels. Table 3 examined differences within the 'theist' group, comparing Cathol $(n=240)$, Anglicans $(n=230)$, other Protestamt $(n=199)$, Jewish $(n=60)$ with agnostic/atherist practitioners.

The table shows that agnostic/atheist practitione were most sympathetic to the idea of AVE and PAS, with Jewish practitioners sympathetic to almost the same degree. Catholic practitioners were most opposed to AVE and to PAS, while Protestant practitioners fell midway between.

Logistic regression analysis was carried out for three of the questions and compared the likeliho of a positive response by practitioners with different religious affiliations compared to agnostics/atheists. The results, shown in Table 4 indicate that groups of 'theists' are slightly less likely to have been asked to hasten death. This was only significanty different for 'other Protestant' and 'others (includieg Moslems)'. Only Catholics were significantly less likely to have taken steps to hasten death, with \$11 other groups of 'theists' only slightly less likety compared to the agnostic/atheist reference group to 


\section{Table 2}

\section{Differences between 'theists' and 'non-theists' in answer to questions about euthanasia}

Question (with number providing answer)

Have been asked to hasten death $(n=1,159)$

If asked have practised AVE $(n=555)$

Know other doctors who practise AVE $(n=1,173)$

It is sometimes right to perform AVE $(n=121)$

Attitude based on secular ethical principles $(n=1,156)$

Physician-assisted suicide sometimes right $(n=1,212)$

Should Australia adopt Netherlands arrangements $(n=1,215)$

Professional organisation should have a euthanasia policy $(n=1,209)$

Law should be changed to allow AVE $(n=1,218)$

Law should be changed to allow PAS $(n=120)$

Would practise AVE if it were legal $(n=1,128)$
Non-theists
percentage

Theists

Adjusted odds

percentage ratio $(95 \% \mathrm{CI}) \#$

$\begin{array}{lll}54 & 43 \cdot 9^{\star} & 1 \cdot 50(1 \cdot 16-1 \cdot 93) \\ 34 \cdot 6 & 24^{\star} & 1 \cdot 62(1 \cdot 09-2 \cdot 38) \\ 68 \cdot 1 & 49 \cdot 3^{\star \star} & 2 \cdot 20(1 \cdot 69-2 \cdot 87) \\ 77 \cdot 9 & 52 \cdot 6^{\star \star} & 3 \cdot 18(2 \cdot 39-4 \cdot 22) \\ 84 \cdot 3 & 57 \cdot 3^{\star \star} & 3.98(2 \cdot 89-5 \cdot 50) \\ 77 \cdot 1 & 48 \cdot 4^{\star \star} & 3 \cdot 57(2 \cdot 70-4 \cdot 74) \\ 78 \cdot 7 & & \\ 72 \cdot 1^{\star \star} & 3 \cdot 39(2 \cdot 54-4 \cdot 52) \\ 70 \cdot 6 & 45 \cdot 5^{\star \star} & 2 \cdot 87(2 \cdot 20-3 \cdot 75) \\ 76 \cdot 8 & 50 \cdot 6^{\star \star} & 3 \cdot 24(2 \cdot 45-4 \cdot 29) \\ 63 & 39 \cdot 4^{\star \star} & 2 \cdot 62(2 \cdot 03-3 \cdot 39) \\ 77 \cdot 6 & 44 \cdot 7^{\star \star} & 4 \cdot 27(3 \cdot 18-5 \cdot 75)\end{array}$

$\star=\mathrm{p}<0.01 ;{ }^{\star}=\mathrm{p}<0.001$.

\#Adjusted odds ratio for non-theists compared with theists using forced entry logistic regression

(adjusted for age, sex, practice).

have done the same. Several 'theist' groups were less likely to think that AVE was sometimes right (Catholic, Anglican, other Protestant, other Christian, 'other [including Moslem]) compared to the agnostics/atheists (Jews were similar to agnostics/atheists across all three questions).

Those who thought AVE was sometimes right based that view on secular ethical principles in 73.5 per cent of cases compared with those who thought that AVE was never right who based their views in $81 \cdot 2 \%$ of cases on religious principles. This was a highly significant $(p<0.001)$ difference.

One question asked where practitioners would turn for advice if faced with a request from a patient to hasten his or her death. While most doctors would seek advice from more than one place (74 per cent of doctors would seek advice from a colleague, 77 per cent from a relative or close friend of the patient, 62 per cent from nursing staff) only 33 per cent would turn to a religious adviser or counsellor for advice. Another question sought information on the values that would go into a decision about euthanasia to which only 22 per cent identified their views as being based primarily on 'ethical principles derived from religious views'.

\section{Discussion}

Almost all this sample of New South Wales medical practitioners answered a question asking for their religious affiliation. Of those who answered, 70 per cent identified themselves with a religious faith and about 30 per cent identified themselves positively as having no such affiliation. That such a high proportion of practitioners were willing to identify their religious affiliation is an indication of the confidence they had in the confidentiality guarantees given with the survey.

As shown in Table 1 the medical practitioners surveyed differed substantially from the population of New South Wales as a whole as regards their religious affiliation, possibly reflecting the selective and socially non-representative nature of recruitment to Australian medical schools. Our survey revealed lower than expected percentages of medical practitioners claiming adherence to the major Christian religions or to Islam, more Jews, Hindus and more agnostic/atheists than expected, and about the expected numbers of Buddhists and Moslems.

A noteworthy difference was the large percentage of doctors on the medical register of New South Wales who were willing to identify themselves as agnostic or atheist. If, as we believe, most medical practitioners grew up in homes which acknowledged some allegiance to a religion, the change in selfperception is likely to have been substantial. Additionally, $2 \cdot 3$ per cent of those who had been born into households in which they received religious training described themselves in the survey as 'lapsed', without choosing to identify themselves as either agnostic or atheist. They did this without there being a specific question on this matter and it is likely that the figure of 'lapsed' doctors obtained by us is an underestimate. The percentage identifying themselves as 'lapsed' is small but would be 
Table 3

\section{Results according to religious affiliation}

Question

Have ever been asked to hasten death

Have practised AVE if asked

Know other physicians who practise AVE

Believe AVE is sometimes right

Base this opinion on secular principles

Believe AVE can be right AND

- base view on secular principles

- base view on religious principles

(number believing AVE can be right)

Believe AVE is not right AND

- base view on secular principles

- base view on religious principles

(number believing AVE never right)

Believe PAS is sometimes right

Think Dutch situation good for Australia

Think professional organisations should adopt a position on euthanasia

Think law should be changed to allow AVE

Think law should be changed to allow PAS

Would practise AVE if it were legal

\begin{tabular}{|c|c|c|c|c|c|c|}
\hline \multicolumn{5}{|c|}{$\%$ answering yes } & \multirow{2}{*}{$\begin{array}{c}\text { chi } \\
\text { square }\end{array}$} & \multirow[b]{2}{*}{$\mathrm{p}$ value } \\
\hline Agnostic & Catholic & Anglican & Other Prot & Jewish & & \\
\hline 54 & 45 & 46 & 43 & 46 & $7 \cdot 98$ & 0.09 \\
\hline 35 & 18 & 28 & 25 & 35 & $10 \cdot 2$ & $0 \cdot 04$ \\
\hline 68 & 48 & 55 & 49 & 60 & 29 & $<0.001$ \\
\hline 78 & 43 & 58 & 48 & 79 & 97 & $<0.001$ \\
\hline 80 & 47 & 59 & 46 & 74 & 98.9 & $<0.001$ \\
\hline 85 & 73 & 78 & 69 & 81 & 28 & $<0.001$ \\
\hline 2 & 15 & 8 & 9 & 5 & 28 & $<0.001$ \\
\hline 265 & 100 & 125 & 86 & 44 & & \\
\hline 81 & 33 & 42 & 32 & 58 & 87 & $<0.001$ \\
\hline 1 & 62 & 51 & 64 & 42 & 87 & $<0.001$ \\
\hline 74 & 117 & 90 & 95 & 12 & & \\
\hline 77 & 45 & 48 & 47 & 70 & 96 & $<0.001$ \\
\hline 79 & 43 & 57 & 47 & 72 & 96 & $<0.001$ \\
\hline 71 & 38 & 49 & 39 & 68 & 87 & $<0.001$ \\
\hline 77 & 42 & 55 & 44 & 77 & 104 & $<0.001$ \\
\hline 63 & 35 & 40 & 32 & 55 & 72 & $<0.001$ \\
\hline 78 & 33 & 50 & 54 & 71 & 125 & $<0.001$ \\
\hline
\end{tabular}

greater than this figure were one to add numbers of those now identifying as atheist or agnostic who were raised initially in a religious home. The numbers of practitioners without religious affiliation may be one result of the critical questioning of authority and belief which is part of the intellectual tradition of tertiary study in Australia. Exclusion or inclusion of those who claimed to be 'lapsed' did not affect the outcomes of analyses.

Of all medical practitioners who had been asked to do so, more than one quarter acknowledged that they had taken steps to hasten death. The prelude to the particular question stated: 'In the following, we wish to focus on the use of active steps to bring about death, as distinct from the withdrawal of lifesustaining treatment'. The actual question asked was: 'Have you ever taken active steps to bring about the death of a patient who asked you to do so?'. So the affirmative responses were from those who were willing to acknowledge that they had done more than cease or withhold potentially curative or lifesustaining treatment. Because of the specific nature of the question it is likely that the figures indicate the minimum percentages of doctors in New South Wales acknowledging that they practise active euthanasia.

The percentages varied significantly with religious affiliation, which appears to be a significant determinant of the practices and of the attitudes of New South Wales medical practitioners to active euthanasia in 1993. Specifically, those doctors claiming to be agnostic or atheist were more likely to favour and to practise euthanasia and those identified with any religion were more likely to be opposed, those most in favour being most likely tô. have taken steps to hasten death and those mo\& opposed being most likely not to have taken suct steps. Of those who did identify with a religion Catholics were significantly different from otheg doctors in the strength and extent of their opposition to AVE. Investigators in the United States have: noted similar findings (12), namely that there an inverse relationship between affiliation wit Catholicism by doctors and support for AVE. This finding is similar to that of Kuhse and Singer in 1988. Like them we did notice, however, that a sma minority of Catholic doctors was willing to recorg that it had assisted patients to hasten death, in spite of quite explicit teachings of the Church to the. contrary. That even 18 per cent of Catholics whioy had been asked to hasten death acknowledged that they had practised AVE was itself noteworthy and raises questions of how these Catholic practitionets reconciled their religious teaching with the responses to the needs of their patients. The resukg showed further the trend of opposition to AVE by a groups with a self-defined religious affiliation.

Morgan Gallup polls of the Australian communit taken sequentially in Australia have shown thig majorities of people surveyed are in favour of AVE, that majority support has persisted over many years of testing, that the percentages in favour are highese (83 per cent) in those with no religious affiliation and 


\section{Table 4}

\section{Relationship between responses to three questions and religious affiliation (analysis compares the likelihood of a positive response compared to the reference group of agnostics/atheists)}

\begin{tabular}{|c|c|c|c|c|c|c|}
\hline \multirow[b]{2}{*}{ Religious group } & \multicolumn{2}{|c|}{$\begin{array}{l}\text { Have been asked } \\
\text { to hasten death }\end{array}$} & \multicolumn{2}{|c|}{$\begin{array}{l}\text { Have taken active steps } \\
\text { to hasten death }\end{array}$} & \multicolumn{2}{|c|}{$\begin{array}{c}\text { Is AVE sometimes } \\
\text { right? }\end{array}$} \\
\hline & $\begin{array}{l}\text { Corrected \# } \\
\text { odds } \\
\text { ratio }\end{array}$ & $\begin{array}{c}95 \% \\
\text { confidence } \\
\text { interval }\end{array}$ & $\begin{array}{l}\text { Corrected \# } \\
\text { odds } \\
\text { ratio }\end{array}$ & $\begin{array}{c}95 \% \\
\text { confidence } \\
\text { interval }\end{array}$ & $\begin{array}{c}\text { Corrected \# } \\
\text { odds } \\
\text { ratio }\end{array}$ & $\begin{array}{c}95 \% \\
\text { confidence } \\
\text { interval }\end{array}$ \\
\hline \multirow{2}{*}{$\begin{array}{l}\text { Agnostics/atheists } \\
\text { (reference group) }\end{array}$} & & & & & & \\
\hline & $1 \cdot 00$ & & $1 \cdot 00$ & & $1 \cdot 00$ & \\
\hline \multicolumn{7}{|c|}{ Measurement of the likelihood of a positive answer from different religious grou } \\
\hline Catholic & 0.73 & $0.53-1.02$ & $0.44^{\star}$ & $0 \cdot 24-0 \cdot 79$ & $0 \cdot 21^{\star}$ & $0 \cdot 15-0 \cdot 30$ \\
\hline Anglican & $0 \cdot 79$ & $0 \cdot 56-1 \cdot 14$ & $0 \cdot 75$ & $0 \cdot 43-1 \cdot 30$ & $0 \cdot 40^{\star}$ & $0 \cdot 27-0 \cdot 58$ \\
\hline Other Protestant & $0 \cdot 66^{\star}$ & $0.46-0.96$ & 0.63 & $0 \cdot 35-1 \cdot 12$ & $0 \cdot 26^{\star}$ & $0 \cdot 18-0 \cdot 38$ \\
\hline 'Christian' & 0.44 & $0 \cdot 17-1 \cdot 15$ & 0.49 & $0 \cdot 10-2 \cdot 50$ & $0 \cdot 16^{\star}$ & $0.06-0.40$ \\
\hline Jewish & $0 \cdot 79$ & $0.44-1.41$ & 0.93 & $0 \cdot 40-2 \cdot 22$ & $1 \cdot 25$ & $0.62-2 \cdot 56$ \\
\hline Other (incl Moslem) & $0 \cdot 50^{\star}$ & $0 \cdot 28-0 \cdot 88$ & 1.06 & $0 \cdot 42-2 \cdot 70$ & $0 \cdot 28^{\star}$ & $0 \cdot 16-0 \cdot 48$ \\
\hline Hindu & 0.68 & $0 \cdot 26-1 \cdot 30$ & 0.51 & $0 \cdot 16-1 \cdot 64$ & $0 \cdot 6$ & $0 \cdot 31-1 \cdot 16$ \\
\hline Buddhist & 0.65 & $0 \cdot 22-1 \cdot 96$ & $0 \cdot 4$ & $0 \cdot 05-3 \cdot 37$ & 1.92 & $0 \cdot 42-8 \cdot 33$ \\
\hline
\end{tabular}

lowest (67 per cent) in Catholics (13). There was a high (two-thirds) level of support for euthanasia from even the least enthusiastic groups within the community in spite of the opposition of official Church teaching to such activity. That 67 per cent of professing Catholics answered yes to the Gallup poll question indicates a disjunction between community attitude and Church teaching on this matter, just as it shows a disjunction between the views of other religions and of those who answered the Gallup poll question.

We have remarked elsewhere that some of the demand for euthanasia may have its origin in the non-availability to some people of highest quality palliative and terminal care. Since such care could be provided if we allocated the service sufficient priority, training and resource, it is reasonable to encourage doctors to address deficiencies in skills and services directed to provision of highest quality palliative and terminal care. Our patients deserve no less and it seems from results we have obtained in this survey that many patients fear what lies ahead of them at the end of life. For those whose religious teachings are opposed, still to endorse and to acknowledge that they practise euthanasia, is one measure of how far our current services and arrangements fall short of what is possible or of what is needed.

\section{Acknowledgements}

The authors acknowledge gratefully the support of the Medical Board of New South Wales, for this study and financial support from the Voluntary Euthanasia Society of New South Wales, of which one of us (PB) is Patron.

Peter Baume, AO, MD, FRACP, FRACGP, FAFPHM, is Professor and Head of the School of Community Medicine, University of New South Wales; Emma O'Malley, BBus (UTS), is Research Associate, and Adrian Bauman, $M B, B S, M P H, P h D$, FAFPHM, is Associate Professor in the School of Community Medicine, University of New South Wales.

\section{References}

(1) Social Responsibilities Committee. Reference paper on euthanasia. Diocese of Adelaide of the Anglican Church of Australia, 1991: 23.

(2) Sacred Congregation for the Doctrine of the Faith. Declaration on euthanasia [Australian ed]. Sydney: St Paul Publications, 1980.

(3) Pope Pius XII. The prolongation of life. In: Horan D J, Mall D, eds. Death, dying and euthanasia. Frederick, Md: Aletheia Books, 1980: 127-134, quoted in Misbin R I. Physicians' aid in dying. New England journal medicine 1991; 325: 1307.

(4) See reference (3): Misbin R I. Jakobovits I. The dying and their treatment in Jewish law: preparation for death and euthanasia. Hebrew medical journal 1961; 2: 242-251.

(5) See reference (3): Misbin R I. Rossner F. Modern medicine and fewish ethics. New York: Yeshiva University Press, 1986: 189.

(6) Apple R R. Euthanasia: Jewish view upholds sanctity of life. Australian fewish times 1989 Apr 7: 11. 
(7) Hady A. Suicide is not a moral right [letter]. Canberra Times 1993 Jul 10.

(8) Wandsborough A. Notes for a discussion paper on euthanasia. Board for Social Responsibility, New South Wales Synod, Uniting Church in Australia, 1993 Oct 14. (The Uniting Church in Australia was formed by the amalgamation of the Methodist, Presbyterian and Congregational Churches.)

(9) Baume P, O'Malley E. Euthanasia: the attitudes and practices of medical practitioners on the medical register of New South Wales. Medical journal of Australia 1994; 161: 137.

(10) SPSS-PC version 5.0. Chicago, Illinois: SPSS Inc, 1990.
(11) Kuhse H, Singer P. Doctors' practices and attitude regarding voluntary euthanasia. Medical journal of Australia 1988; 148: 623-627.

(12) Anderson J G, Cadell D P. Attitudes of medicas practitioners towards euthanasia. Social science and: medicine 1993; 37: 105.

(13) Morgan Poll (incorporating the Morgan Gallup Poll) finding number 2436. Majority support for euthanasia 1993 Jun 28.

(14) Australian Bureau of Statistics. 1991 Census. Religio by sex. Publication 2722.0.

\section{News and notes}

\section{Student paper competition: call for papers}

The Student Interest Group of the Society for Health and Human Values is sponsoring a call for studentwritten papers in bioethics on the broad subject: Values and Health Care: Diverse Perspectives. The winner will receive a $\$ 1,000$ award, plus up to $\$ 150$ for expenses incident to presenting the paper at the SHHV annual meeting in San Diego, California, October 12-15 1995.

The topic could be addressed from the perspectives of such disciplines as philosophy, sociology, economics, law, journalism, anthropology, political science, theology, religious studies, literature, visual arts, nursing, or feminist or women's studies.

The following sample questions are offered to illustrate a few ways in which the topic might be approached:

What impact should bioethics have on public policy?

How does the fact-value distinction affect medical practice or bioethics?
How can we include diversity in moral and/or medical education in a meaningful way, without merely falling victim to the buzzword syndrome of the 1990s?

What should the relationship be between feminist analysis in bioethics and the ethic of care?

How can a deeper understanding of environmento ethics inform the broader bioethics debate?

Papers must be documented, original, scholarly work of a single author, and must not already have been published or accepted for publication; submissions must not exceed 15 typed, double-space pages and must be postmarked no later than April 15, 1995. For eligibility and submission requirements, please contact; Merrill Watson, Student Interest Group Program Chair, SHHV PO Box 488, Haslett, MI 48840-0488: 517-339-1077 E-mail: ae 763@detroit.freenet.org. 